\section{Structure versus anticoagulant and antithrombotic actions of marine sulfated polysaccharides}

\author{
Vitor Hugo Pomin, * Paulo Antônio de Souza Mourão \\ Programa de Glicobiologia, Instituto de Bioquímica Médica, Hospital Universitário \\ Clementino Fraga Filho, Universidade Federal do Rio de Janeiro, Brazil.
}

Revista Brasileira de Farmacognosia Brazilian Journal of Pharmacognosy 22(4): 921-928, Jul./Aug. 2012

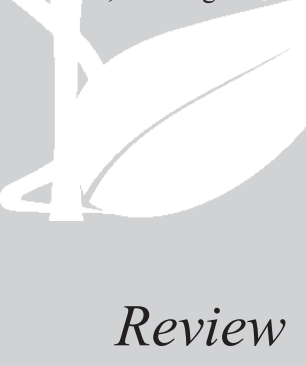

\begin{abstract}
Marine sulfated polysaccharides (MSP), such as sulfated fucans (SF), sulfated galactans ( $\mathrm{SG}$ ) and glycosaminoglycans (GAG) isolated from either algae or invertebrate animals, are highly anionic polysaccharides capable of interacting with certain cationic proteins, such as (co)-factors of the coagulation cascade during clotting-inhibition processes. These molecular complexes between MSP and coagulation-related proteins might, at first glance, be assumed to be driven mostly by electrostatic interactions. However, a systematic comparison using several novel sulfated polysaccharides composed of repetitive oligosaccharides with clear sulfation patterns has shown that these molecular interactions are regulated essentially by the stereochemistry of the glycans (which depends on a conjunction of anomericity, monosaccharide, conformational preference, and glycosylation and sulfation sites), rather than just a simple consequence of their negative charge density (mainly the number of sulfate groups). Here, we present an overview of the structure-function relationships of MSP, correlating their structures with their potential anticoagulant and antithrombotic actions, since pathologies related to the cardiovascular system are one of the major causes of illness and mortality in the world.
\end{abstract}

Received 21 Dec 2011
Accepted 23 Jan 2012

Available online 24 May 2012

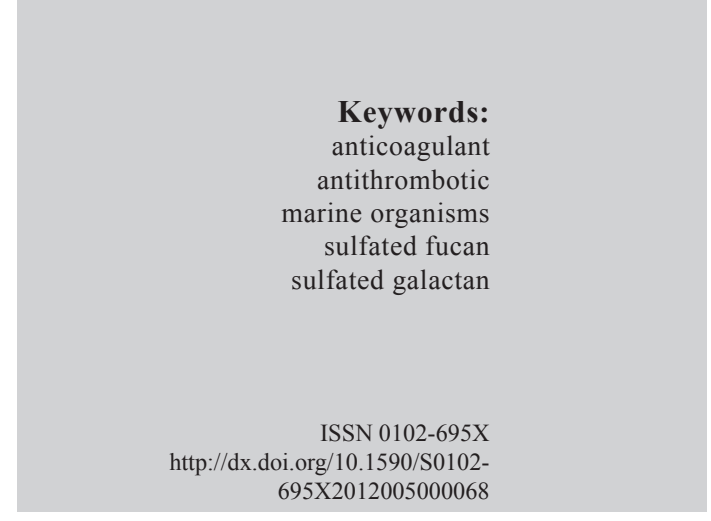

\section{Introduction}

The trends for regular chemical structures in invertebrates and red algae

The efforts in both structural and functional studies of marine sulfated polysaccharides (MSP) have been increasing significantly over the last ten years (Pomin, 2008; Pomin \& Mourão, 2008). This attention is a consequence of the great interest in novel sulfated polysaccharides (SP) such as glycosaminoglycans (GAG). GAG are of particular interest to researchers looking for alternative and/or safer sources of heparin (Mourão \& Pereira, 1999). Heparin has been the most clinically exploited anticoagulant over the last 50 years (Fareed et al., 2000). Until the early 90's, sulfated fucans (SF), homopolymers of fucopyranosyl units exclusively in the $\alpha$-L-form (Pomin, 2008; Pomin \& Mourão, 2008), and sulfated galactans (SG), homopolymers of $\alpha$-L- or $\alpha$-Dand/or $\beta$-D-galactopyranosyl units (Pomin, 2009), were usually extracted and characterized from the cell walls of the three major groups of macroalgae. Phaeophyta (brown algae) expresses SF, while Rhodophyta (red algae) and Chlorophyta (green algae) both express SG.

Historically, algal SF and SG are used mainly in clinical tests and large-scale extractions for industrial purposes. Recently, however, new and interesting sources of these compounds have been found in the extracellular matrices of certain marine invertebrates (Mourão \& Pereira, 1999; Mourão, 2004; 2007; Pomin, 2008; 2009; Pomin \& Mourão, 2008). In contrast with most algal sulfated polysaccharides, the invertebrate polymers exhibit highly regular chemical structures (Figure 1 and 2A-D), which make it easier to correlate their biological functions with their respective structural features (Pomin, 2008; Pomin \& Mourão, 2008; Vilela-Silva et al., 2008). This is of enormous benefit to the entire field of glycobiology. At one time, it was relatively hard to develop accurate structure-activity relationships for the majority of SPs. This same advantage is also observed for some marine invertebrate GAG (Figure 2F).

In contrast, many mammalian GAG exhibit a large variety of sulfation patterns (Gandhi \& Mancera, 2008) and, consequently, demand much more effort to assay their biological activities, determine their specific structural features and subsequently propose a dependable structure-function relationship.

The MSP with well-defined chemical structures (SF, SG and GAG in Figures 1 and 2) are extracted from echinoderms (Echinodermata) like sea cucumbers 
(A) L. grisea

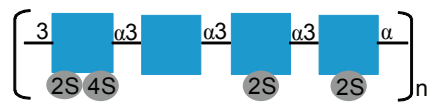

(B) L. variegatus

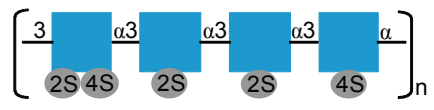

(C) S. pallidus

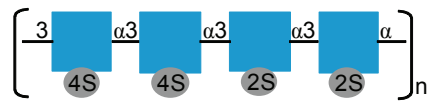

(D) A. lixula

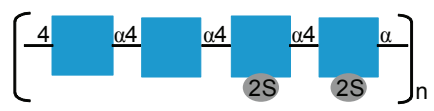

(E) S. purpuratusI (F). purpuratus II

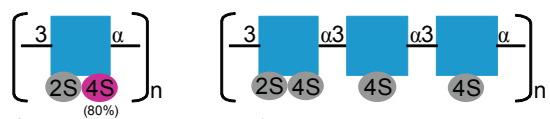

(G) S. droebachiensis $(H)$. franciscanus
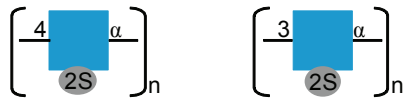

L-Fucp

sulfation

$\%$ of sulfation

Figure 1. Chemical structures of the repeat units of the SFs from the cell wall of the sea-cucumber (A) and from the egg jelly coat of sea-urchins (B-H). These polysaccharides are composed of $\alpha$-L-fucopyranosyl units (light blue squares). The speciesspecific structures vary in the sulfation patterns (exclusively 2and/or 4-positions, in glycosidic linkages: $\alpha(1 \rightarrow 3)(\mathrm{A}-\mathrm{C}, \mathrm{E}, \mathrm{F}$ and $\mathrm{H})$ and $\alpha(1 \rightarrow 4)(\mathrm{D}$ and $\mathrm{G})$, and in the number of residues of the repeat units: tetrasaccharides (A-D), trisaccharides (F) and monosaccharides $(\mathrm{E}, \mathrm{G}$ and $\mathrm{H})$, but they are all linear. The numbers over the thin black lines represent the glycosodic linkage. The gray and violet ellipses represent the site and \% of sulfation, respectively. The numbers before $\mathrm{S}$ inside the ellipses represent the sulfation position. The structures are the following: (A) Ludwgothurea grisea (Selenka, 1867) $[\rightarrow 3)$ - $\alpha$-L-Fuc $p-2,4\left(\mathrm{OSO}_{3}-\right.$ )-( $(1 \rightarrow 3)-\alpha$-L-Fuc $p$ - $(1 \rightarrow 3)-\alpha-L-F u c p-2\left(\mathrm{OSO}_{3}-\right)-(1 \rightarrow 3)-\alpha$-L-Fucp$2\left(\mathrm{OSO}_{3}-\right)-(1 \rightarrow]_{\mathrm{n}}$ (Mulloy et al., 2004); (B) Lytechinus variegatus (Leske, 1778$) \quad[\rightarrow 3)-\alpha-\mathrm{L}-\mathrm{Fuc} p-2,4\left(\mathrm{OSO}_{3}-\right)-(1 \rightarrow 3)-\alpha-\mathrm{L}-\mathrm{Fuc} p$ $2\left(\mathrm{OSO}_{3}-\right)-(1 \rightarrow 3)-\alpha-\mathrm{L}-\mathrm{Fuc} p-2\left(\mathrm{OSO}_{3}-\right)-(1 \rightarrow 3)-\alpha-\mathrm{L}-\mathrm{Fuc} p-4\left(\mathrm{OSO}_{3}-\right.$ )-(1 $\rightarrow]_{\mathrm{n}}$ (Pomin \& Mourão, 2008); (C) Strongylocentrotus pallidus (G. O. Sars, 1871) $[\rightarrow 3)-\alpha-\mathrm{L}-\mathrm{Fuc} p-4\left(\mathrm{OSO}_{3}-\right)-(1 \rightarrow 3)-\alpha-$ L-Fuc $p-4\left(\mathrm{OSO}_{3}-\right)-(1 \rightarrow 3)-\alpha-\mathrm{L}-\mathrm{Fuc} p-2\left(\mathrm{OSO}_{3}-\right)-(1 \rightarrow 3)-\alpha-\mathrm{L}-\mathrm{Fucp}-$ 2( $\left(\mathrm{OSO}_{3}-\right)-(1 \rightarrow]_{\mathrm{n}}$ (Vilela-Silva et al., 2002); (D) Arbacia lixula (Linnaeus, 1758$) \quad[\rightarrow 4)-\alpha-\mathrm{L}-\mathrm{Fuc} p-2\left(\mathrm{OSO}_{3}-\right)-(1 \rightarrow 4)-\alpha-\mathrm{L}-\mathrm{Fuc} p$ $2\left(\mathrm{OSO}_{3}-\right)-(1 \rightarrow 4)-\alpha-\mathrm{L}-\mathrm{Fuc} p-(1 \rightarrow 4)-\alpha-\mathrm{L}-\mathrm{Fuc} p-(1 \rightarrow]_{\mathrm{n}} \quad$ (Alves et al., 1997); (E) Strongylocentrotus purpuratus-I (Stimpson, 1857) $\sim 80 \% \quad[\rightarrow 3)-\alpha-L-F u c p-2,4\left(\mathrm{OSO}_{3}-\right)-(1 \rightarrow]_{\mathrm{n}}$ and $\sim 20 \%[\rightarrow 3)-\alpha-$ L-Fucp- $2\left(\mathrm{OSO}_{3}-\right)-(1 \rightarrow]_{\mathrm{n}}$ and $(\mathrm{F}) \quad S$. purpuratus $-\mathrm{II}[\rightarrow 3)-\alpha-\mathrm{L}-$ Fuc $p-2,4\left(\mathrm{OSO}_{3}-\right)-(1 \rightarrow 3)-\alpha-\mathrm{L}-\mathrm{Fuc} p-4\left(\mathrm{OSO}_{3}-\right)-(1 \rightarrow 3)-\alpha-\mathrm{L}-\mathrm{Fuc} p$ $4\left(\mathrm{OSO}_{3}-\right)-(1 \rightarrow]_{\mathrm{n}}$ (Alves et al., 1998); (G) Strongylocentrotus droebachiensis (O. F. Müller, 1776) $[\rightarrow 4)-\alpha-\mathrm{L}-\mathrm{Fuc} p-2\left(\mathrm{OSO}_{3}-\right.$ )$-(1 \rightarrow]_{\mathrm{n}}$ (Vilela-Silva et al., 2002); and $(\mathrm{H})$ Strongylocentrotus franciscanus (A. Agassiz, 1863) [3)- $\alpha-\mathrm{L}-\mathrm{Fuc} p-2\left(\mathrm{OSO}_{3}-\right)-(1 \rightarrow]_{\mathrm{n}}$ (Vilela-Silva et al., 1999).
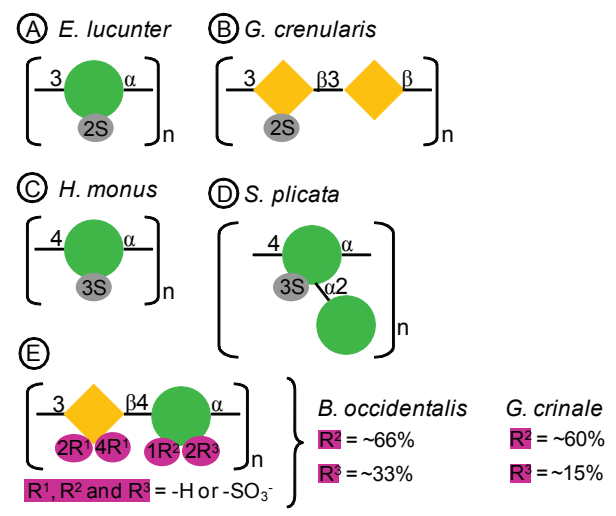

(F)

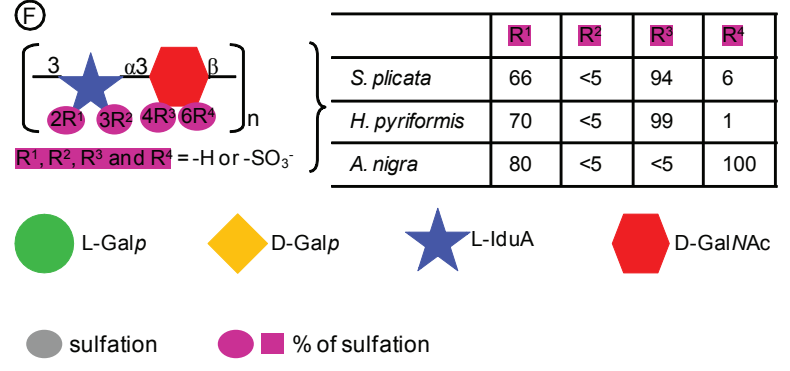

Figure 2. Chemical structures of the repeat units of SG from the egg jelly coat of sea-urchins (A and B), from the tunic of ascidians $(C$ and $D)$, and from red algae $(E)$; and of the repeat units of DS from ascidians (F). These polysaccharides are composed of L-galactopyranoses (green circles), D-galactopyranoses (yellow diamond), L-iduronic acids (blue star), and D-Nacetylgalactosamines (red hexagons). The numbers over the thin black lines represent the glycosodic linkage. The gray and violet boxes and ellipses represent the site and \% of sulfation, respectively. The numbers before $S$ and $R$ inside the ellipses represent the positions of sulfation or radicals. The superscripted numbers after $R$ represents the respective radical. The structures are the following: (A) Echinometra lucunter (Linnaeus, 1758) [3)$\alpha$-L-Galp-2(OSO $\left.{ }^{-}\right)-(1 \rightarrow]_{\mathrm{n}}$ (Alves et al., 1997); (B) Glyptocidaris crenularis (A. Agassiz, 1863) $\left[\rightarrow 3-\beta-\mathrm{L}-\mathrm{Gal} p-2\left(\mathrm{OSO}_{3}-\right)-1 \rightarrow 3-\beta-\mathrm{L}-\right.$ Galp-1 $\rightarrow]_{\mathrm{n}}$ (Castro et al., 2009); (C) Herdmania monus (Savigny, 1816) $[\rightarrow 4)-\alpha-\mathrm{L}-\mathrm{Gal} p-3\left(\mathrm{SO}_{3}-\right)-(1 \rightarrow]_{\mathrm{n}}$ (Santos et al., 1992); (D) Styela plicata (Lesueur, 1823). $\{\rightarrow 4)-\alpha-\mathrm{L}-\mathrm{Gal} p-2[\rightarrow 1)-\alpha$-L$\left.\mathrm{Gal} p-3\left(\mathrm{OSO}_{3}-\right)\right]-3\left(\mathrm{OSO}_{3}-\right)-(1 \rightarrow\}_{\mathrm{n}}$ (Mourão \& Perlin, 1987); (E) both Botryocladia occidentalis (Kylin, 1931) and Gelidium crinale (Gaillon 1828) express [3- $\beta$-D-Gal $p-1 \rightarrow 4-\alpha-\mathrm{Gal}-1 \rightarrow]_{\mathrm{n}}$ with different sulfation contents (Pereira et al., 2005; Fonseca et al., 2008); and (F) the DS from Styela plicata, Halocynthia pyriformis (Rathke, 1806), and Ascidian nigra (Savigny, 1816) are composed of [4- $\alpha$-L-IdoA-1 $\rightarrow 3-\beta-D-G a l N A c-1]_{n}$ with also different sulfation patterns (Pavão et al., 1995; Pavão et al., 1998).

(Holothuroidea) (Mulloy et al. 2004) and sea urchins (Echinoidea) (Pomin \& Mourão, 2008; Vilela-Silva et al., 2008) or ascidians (Urochordata, Ascidiacea) (Mourão \& Perlin, 1987; Santos et al., 1992; Pavão et al., 1995; Pavão et al., 1998; Vicente et al., 2001; Pavão, 2002). The SF (Figure 1B-H) and SG (Figure 2A and B) are widespread throughout the jelly coat that surrounds 
sea urchin eggs. As discussed below, these particular MSP are physiologically responsible for controlling the external fertilization in sea urchins in a very restrictive species-specific manner (Mourão, 2007; Vilela-Silva et al., 2008). Among all the MSP with well-defined chemical structures described so far (Figures 1 and 2), there is a single description from the body wall of the sea cucumber (Figure 1A) (Mulloy et al., 2004), a few examples of SG isolated from the tunic of ascidians (Figure 2C and 2D) (Mourão \& Perlin, 1987; Santos et al., 1992; Pavão et al., 1998), and some reports from specific red algal cell walls (Figure 2E) (Pereira et al., 2005; Fonseca et al., 2008). All of the remaining structures (Figure 1B-H and 2A and B) belong to the egg jelly coat of sea urchins (Alves et al., 1997; Alves et al., 1998; Vilela-Silva, et al., 1999; Vilela-Silva et al., 2002; Mulloy et al., 2004) The body of some species of ascidians also contains peculiar GAG that show sulfation patterns distinct from mammalian GAG (Pavão et al., 1995; Pavão et al., 1998), as exemplified by the tunicate dermatan sulfates (DS) in Figure 2F.

\section{The interaction of MSPs with coagulation (co)-factors: stopping blood coagulation}

Unrelated to their natural biological role as inducers of fertilization, the SF and SG also exhibit potential pharmacological actions in mammalian systems. Among several clinical activities such as antiviral, antimetastatic, anti-angiogenic, anti-inflammatory, and anti-adhesive (Coombe et al., 1987; Harrop et al., 1992; Cumashi et al., 2007), the anticoagulant and antithrombotic actions are the most explored so far (Farias et al., 2000; Pomin, 2008). This is due to a pressing need for new antithrombotic drugs as a consequence of the increasing incidence of thromboembolic diseases. In fact, cardiovascular diseases are the leading cause of death worldwide (30\% of total causes) (Mourão \& Pereira, 1999; Pereira et al., 1999; Farias et al., 2000; Pereira et al., 2002a,b; Berteau \& Mulloy, 2003; Mourão, 2004; Pereira et al., 2005; Becker et al., 2007; Cumashi et al., 2007; Pomin, 2008; 2009; Pomin \& Mourão, 2008).

The SF and SG show great advantages as alternative sources for anticoagulant therapies, especially because of the massive use of heparin (Fareed et al., 2000). This mammalian GAG has the highest negative charge density ever found in a natural molecule. It is also well known to present several limitations due to collateral effects and limited sources of material (Mourão, 2004). The situation has been complicated recently due to the alarming discovery of heparin preparations that have been contaminated with oversulfated chondroitin sulfate (Guerrini et al., 2008). This contaminant induces hypotension associated with kallikrein release when administered by intravenous injection (Kishimoto et al., 2008). Fatal cases have been described.
The new MSP (Figures 1 and 2) offer some advantages over heparin. They show considerably lower contamination levels of virus and/or prions because they are exclusively extracted from marine sources. Contamination in clinical solutions of heparin can occur more easily since this compound is extracted from mammalian sources, like porcine and bovine intestinal mucosa and bovine lung (Mourão, 2004). Moreover, the invertebrate MSP have the potential of being more useful as clinical reagents than algal SP due to their regular and well-defined structures (Mourão, 2004; Pomin, 2008; Pomin \& Mourão, 2008), even though algal molecules have been utilized more until now.

In addition to all the benefits described above, the very clear and regular structures of invertebrate SF (Figure 1) and SG (Figure 2A-D), the algal SG (Figure 2E) and the ascidian GAG (Figure 2F) enable determination of well-defined structure-function relationships (Pomin, 2008; Pomin \& Mourão, 2008). This knowledge allows prediction of the major molecular features involved in molecular interactions such as those between the MSP and blood (co)factors, similar to the use in the fertilization assays mentioned in the previous section. The anticoagulant action of the SP resides mainly in the potentiation of natural inhibitors of plasma proteases. The plasma proteases include activated factor II (IIa, commonly known as thrombin) and activated factor $\mathrm{X}(\mathrm{Xa})$. Inhibitors include the serpins (antithrombin, AT; and heparin cofactor II, HCII). The catalysis of SP can be classified into two distinct mechanisms: (i) the allosteric change of the serpins induced by the SP; and (ii) the template mechanisms, where the glysidic chain of the SP can act as a "bridge" that brings together both protease and serpin. The mechanisms for AT and HCII are illustrated in Figures $3 \mathrm{~A}$ and $3 \mathrm{~B}$, respectively.

Next we will describe particular cases of how each specific structural feature of the MSP (Figures 1 and 2) can individually account for different levels of activity and interaction with serpins and/or blood proteases (Figure 3). This results in differing kinetics of preventing clot formation. The particular structural contributions of the MSP can be properly recognized when the anticoagulant properties of these biopolymers are systematically compared. In addition, the results might offer qualitatively accurate data. This systematic comparison was carried out by two in vitro anticoagulant assays: (i) the aPTT (activated partial thromboplastin time), which measures the general anticoagulant effect when all the plasma proteins are included, and (ii) the direct measurement of the inhibition level of factors IIa or Xa by AT or HCII in the presence of the MSP. Results from these assays are compiled in Table 1. 
(A)

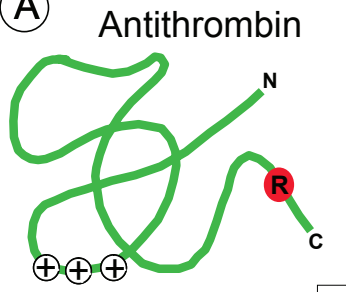

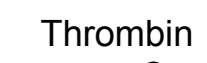

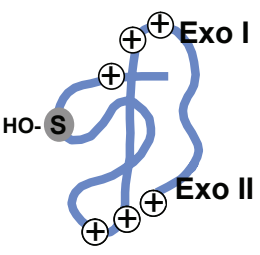

(B)

Heparin cofactor II
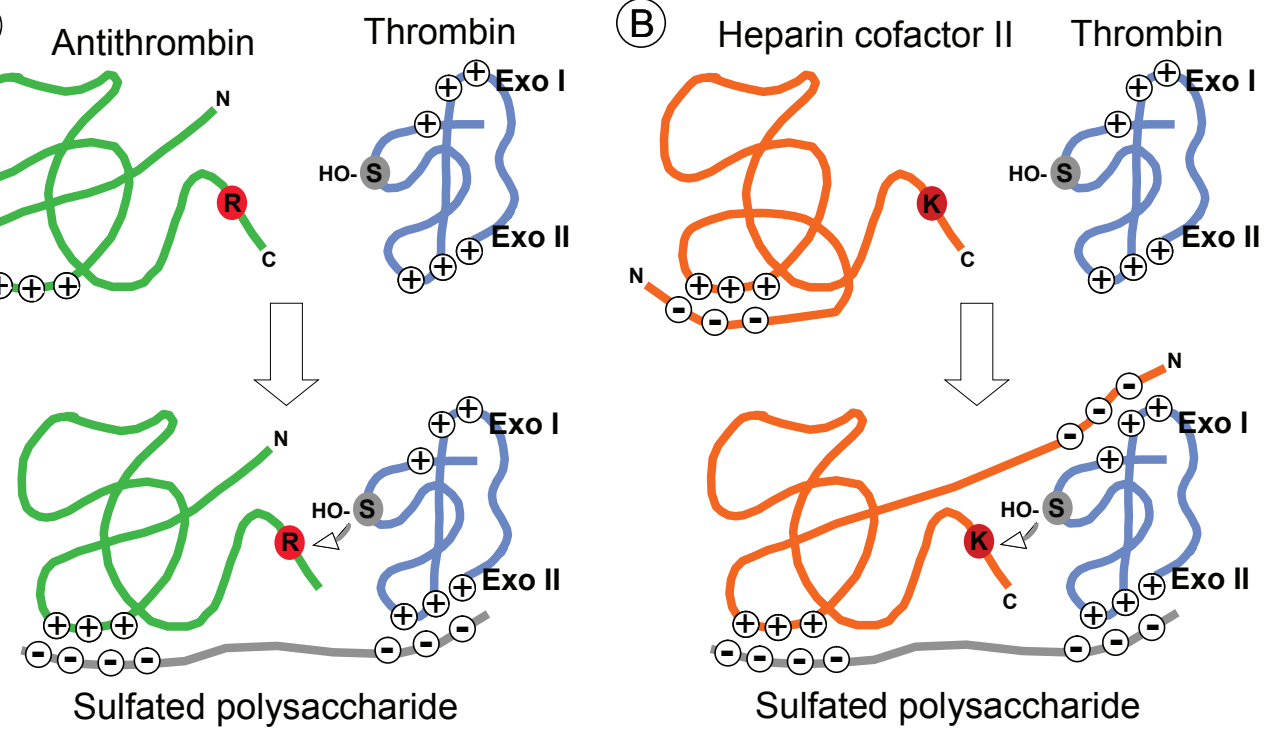

Figure 3. Molecular schematic representation of the anticoagulant mechanisms of SP. The thrombin (IIa, in blue) can be inhibited by serpins such as antithrombin (AT, in green) or heparin cofactor-II (HC-II, in orange). In both cases, the SP (gray line) brings together the serpins and protease-IIa mainly through electrostatic interactions of their opposite charges. In the thrombin, this charged cluster is the EXO II. Next, the hydroxyl groups of a serine (S) residue from thrombin will bind to the $\mathrm{C}$-terminus of the serpins, actually to an arginine (R) residue of the AT (A), or to a lysine (K) residue in the case of HC-II (B). In the bound-states, a conformational change occurs in both serpins, although this change is more predominant and necessary in the HC-II case. (B) Note that the N-terminus of HC-II also interacts with the EXO I of IIa, also through electrostatic contacts. With the examples described throughout the text, it is clear that the template mechanisms between SP (SF, SG, GAG), serpins (AT, HC-II) and protease (IIa) have differential stabilities or formation kinetics that are directly related to the structural features of the SP.

Influential structural features of MSP in interactions with coagulation (co)-factors

\section{Monosaccharide type-dependent case}

Comparing all the structures in Figures 1 and 2, one can discern structural similarities and differences in the SF and SG. For example, both SF from Strongylocentrotus franciscanus (Figure 1H), and SG from Echinometra lucunter (Figure 2A) present the same sulfation pattern (exclusive and entirely 2-sulfated), the same anomeric configuration ( $\alpha$-form), the same glycosidic linkage $(1 \rightarrow 3)$ and the same molecular mass $(\sim 100 \mathrm{kDa})$. Their single difference is their sugar type (fucopyranose or galactopyranose, respectively) (Pomin, 2008). Interestingly, this single structural difference is itself enough to promote great changes in the anticoagulant properties of these homopolysaccharides. The 2-sulfated $\alpha$-galactan from E. lucunter exhibits a significant anticoagulant activity (aPTT of $20 \mathrm{IU} \mathrm{mg}$, although almost 10-fold less than UFH, Table 1). The specific anticoagulant assay with the purified proteases revealed that this SG enhances both IIa and factor Xa inhibition by either AT or HCII (Table 1). On the other hand, the anticoagulant effect of 2 -sulfated $\alpha$-fucan from
S. franciscanus is exclusively based on catalysis of AT inhibition over factor $\mathrm{Xa}$, although it is 12.5 -fold less active than the $\alpha$-SG. This single effect on the Xa/AT system explains the much lower activity of the compound from $S$. franciscanus (aPTT of $\sim 2 \mathrm{IU} \mathrm{mg}^{-1}, 100$-fold less active than UFH) since the anti-Xa activity has a relatively minor influence on the aPTT. This is an illustrative and typical example of a sugar-type-dependent biological effect of polysaccharides.

\section{Preferential conformation binding-dependent case}

Interaction energies obtained from molecular dynamics (MD) simulations are statistically equivalent for both the 2-sulfated $\alpha$-L-galactan from $E$. lucunter (Figure 2A) and the 2-sulfated $\alpha$-L-fucan from $S$. franciscanus (Figure 1H). This would be expected based on the structural similarities of these two compounds, especially their conformations in solution. However, they revealed markedly different interactions for binding with the complex AT/IIa. The explanation for this result is the extreme difference in orientation on the AT binding site $\left(\sim 90^{\circ}\right.$, Figures $4 \mathrm{C}$ and $\left.4 \mathrm{D}\right)$. Such a difference in orientation upon binding to AT explains the lack of activity of SF under the same experimental conditions 
and fully supports the expected bridging mechanism for the activity of SG, as previously described (Melo et al., 2004). Thus, both compounds are capable of interacting with AT, as indicated by theoretical results and experimental data showing that both polysaccharides are retained on an AT-affinity column. However, only the complex formed by SG and AT (Figure 4D) allows further interaction with IIa. An analogous complex is the ternary

Table 1. Anticoagulant activities of MSPs measured by APTT and by IC50 for thrombin (IIa) and factor Xa inhibition in the presence of antithrombin (AT) or Heparin Cofactor II (HCII) (Pavão et al., 1998; Mourão \& Pereira, 1999; Mourão, 2004; Pereira et al., 2005; Fonseca et al., 2008).

\begin{tabular}{|c|c|c|c|c|c|c|}
\hline \multirow{2}{*}{ Polysaccharide } & \multirow[t]{2}{*}{ Source } & \multirow[t]{2}{*}{ Structure (Figure) } & \multirow[t]{2}{*}{ APTT (IU/mg) } & \multicolumn{3}{|c|}{$\mathrm{IC} 50(\mu \mathrm{g} / \mathrm{mL})$} \\
\hline & & & & $\mathrm{IIa} / \mathrm{AT}$ & $\mathrm{IIa} / \mathrm{HCII}$ & $\mathrm{Xa} / \mathrm{AT}$ \\
\hline \multirow[t]{6}{*}{ 3-linked sulfated $\alpha$-L-fucans } & S. purpuratus (I) & $1 \mathrm{E}$ & 76 & 0.3 & 0.3 & 2 \\
\hline & S. purpuratus (II) & $1 \mathrm{~F}$ & 10 & 0.9 & 2 & ND \\
\hline & S. pallidus & $1 \mathrm{C}$ & 18 & $>500$ & $>500$ & $>500$ \\
\hline & L. variegatus & 1B & 3 & $>500$ & $>500$ & $>500$ \\
\hline & S. franciscanus & $1 \mathrm{H}$ & $\sim 2$ & $>500$ & $>500$ & 250 \\
\hline & L. grisea & $1 \mathrm{~A}$ & $<1$ & $>500$ & $>500$ & $>500$ \\
\hline \multirow[t]{2}{*}{ 4-linked sulfated $\alpha$-L-fucans } & S. droebachiensis & $1 \mathrm{G}$ & $<1$ & ND & ND & ND \\
\hline & A. lixula & $1 \mathrm{D}$ & $\sim 2$ & 150 & 150 & $>500$ \\
\hline \multirow[t]{3}{*}{ sulfated $\alpha$-L-galactans } & E. lucunter & $2 \mathrm{~A}$ & 20 & 3 & 6 & 20 \\
\hline & H. monus & $2 \mathrm{C}$ & $\sim 2$ & $>500$ & $>500$ & $>500$ \\
\hline & S. plicata & $2 \mathrm{D}$ & $<1$ & $>500$ & $>500$ & $>500$ \\
\hline \multirow[t]{2}{*}{ algal $\mathrm{SG}^{\mathrm{c}, \mathrm{d}}$} & B. occidentalis & $2 \mathrm{E}$ & 93 & 0.02 & 1.1 & 2.5 \\
\hline & G. crinale & & 65 & 0.02 & 25 & 1.5 \\
\hline \multirow[t]{3}{*}{ ascidian $\mathrm{DS}^{\mathrm{e}}$} & S. plicata & $2 \mathrm{~F}$ & 8 & inactive & 0.31 & inactive \\
\hline & H. pyriformis & & 11 & inactive & 0.35 & inactive \\
\hline & A. nigra & & $<5$ & inactive & 320 & inactive \\
\hline mammalian & native & & 2 & $\mathrm{nr}^{\mathrm{b}}$ & 3 & $\mathrm{nr}$ \\
\hline standard $\mathrm{DS}^{\mathrm{e}}$ & oversulfated & & 13 & $\mathrm{nr}$ & 2 & $\mathrm{nr}$ \\
\hline
\end{tabular}

${ }^{\mathrm{a}}$ The activity is expressed as international units/mg using a parallel standard curve based on the International Heparin Standard (193 units/mg); ${ }^{\mathrm{b}}$ Not reported, ${ }^{\mathrm{c}} \mathrm{Pereira}$ et al., 2005; 'ंFonseca et al., 2008; 'Pavão et al., 1998.

(A)

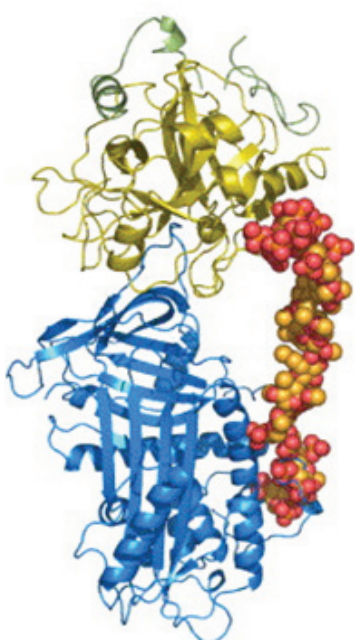

(B)
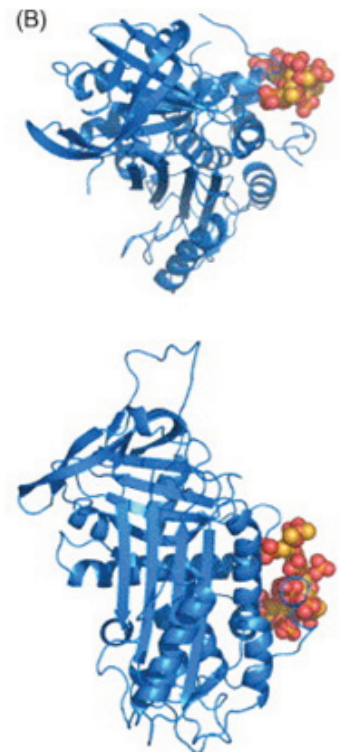

(C)
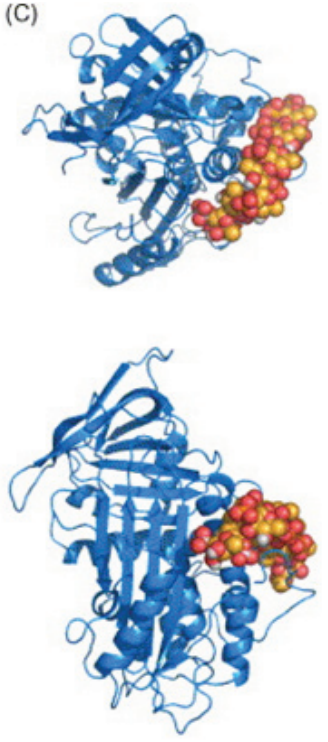

(D)
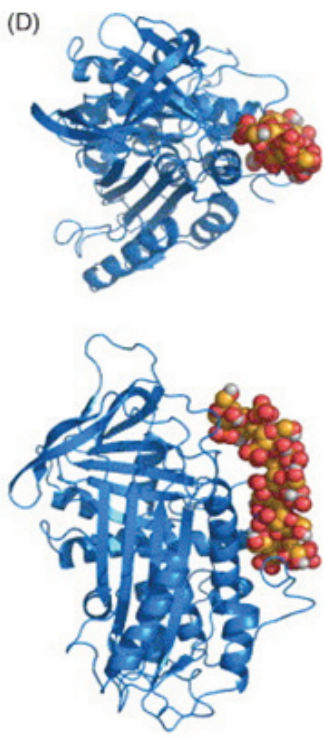

Figure 4. Structures of the complexes between different SP and AT. (A) ternary complex between AT, thrombin and a heparin derivative (PDB ID 1TB6); (B) AT bonded to the synthetic pentasaccharide (PDB ID 1E03); (C) final structure from a $5 \mathrm{~ns}$ MD of AT complexed to a SF decasaccharide with pyranose rings; (D) final structure from a $5 \mathrm{~ns}$ MD of AT complexed to a SG decasaccharide with pyranose rings. For (B)-(D), two orientations of the complexes are presented. Data from Becker et al. (2007). 
complex between heparin-AT-IIa (Figure 4A), which supports the potentiation of this protease inactivation by AT in the presence of SG. This is an example of how the orientational constraints in solution can influence spatial preferences of the SP for their different bindings with target proteins (Melo et al., 2004). It is obvious that the difference in the sugar type drastically changes the conformation of the polymer as well, implying a different conformational binding, as explained in this section.

\section{Sulfation pattern-dependent case}

Based on this same systematic comparison, the SG from the red algal species Botryocladia occidentalis and Gelidium crinale exhibit identical backbones and the same chain size. However, there are slight differences in their sulfation patterns (Figure 2E). As a consequence of this difference, the two algal SG differ in their anticoagulant and venous antithrombotic activities, as previously described (Fonseca et al., 2008). SG from $G$. crinale exhibit pro-coagulant and pro-thrombotic effects in low doses (up to $1.0 \mathrm{mg} / \mathrm{kg}$ body weight). At high doses $(>1.0 \mathrm{mg} / \mathrm{kg})$, this polysaccharide inhibits both venous and arterial thrombosis in rats. In contrast, SG from $B$. occidentalis is a very potent anticoagulant and antithrombotic compound in low doses (up to 0.5 $\mathrm{mg} / \mathrm{kg}$ body weight), inhibiting experimental venous thrombosis, but these effects are reverted at high doses. Conversely, arterial thrombosis is only inhibited at high doses $(>1.0 \mathrm{mg} / \mathrm{kg})$ of the polysaccharide from B. occidentalis. These results indicate that slight differences in the proportions and/or distribution of sulfated residues along the galactosyl chain may be critical for the interaction between proteases, inhibitors, and activators of the coagulation system, resulting in a distinct pattern in the anti- and pro-coagulant activities and in the antithrombotic action. As summarized in Table 1, these structural differences account for the $30 \%$ difference in anticoagulant activity (aPTT) of these algal macromolecules and the even greater difference in catalytic effect of the sulfated polysaccharide on HCII-mediated anti-IIA activity.

Indeed, the structural requirements for the interaction of these SP with the coagulation cofactors and their target proteases and inhibitors are stereospecific (Mourão \& Pereira, 1999; Mourão, 2004; Pomin, 2008; Pomin \& Mourão, 2008). The site of sulfation has a major impact on activity. This can be illustrated by the fact that 2,4-di-sulfated units have an amplifying effect on the AT-mediated anticoagulant activity in the series of 3-linked $\alpha$-L-fucans (Figure 1, Table 1). Specific sulfation sites are required for the interaction with plasma serineprotease inhibitors. Note the occurrence of the 4-sulfated unit content in the 3-linked $\alpha$-L-fucans: L. variegatus (a single 4-sulfated unit/tetrasaccharide - Figure 1B), $S$. pallidus (a double 4-sulfated unit/tetrasaccharide - Figure $1 C$ ), and $S$. purpuratus, isotype II (a double 4-sulfated unit/trisaccharide - Figure 1F). This 4-sulfation is the structural motif required to enhance the inhibition of IIa by HCII. In contrast, the presence of 2-sulfated residues seems to have a deleterious effect on HCII-mediated antiIIA activity of the polysaccharides (Mourão, 2004).

Ascidian DS with the backbone structure [4- $\alpha-$ L-IdoA- $1 \rightarrow 3-\beta$-D-GalNAc-1 $]_{n}$ but with different patterns of sulfation (Figure 2F) also reveal different anticoagulant activities (Table 1) (Pavão et al., 1995; Pavão et al., 1998; Vicente et al., 2001). They are also useful and reliable cases to describe the influence of sulfation sites on biological actions. All three ascidian DSs have a high content of 2-O-sulfated $\alpha$-L-iduronic acid residues, but differ in the pattern of sulfation of the $N$-acetyl- $\beta$-D-galactosaminyl units. Styela plicata and Halocynthia pyriformis have 4- $O$-sulfated units, but in Ascidian nigra they are 6- $O$ sulfated. This collection of ascidian DS, where the extent and position of sulfate substitution have been well characterized, was examined in anticoagulant assays. DS from A. nigra has no discernible anticoagulant activity, which indicates that 4-O-sulfation of the $N$-acetyl- $\beta$-Dgalactosamine is essential for that activity (Table 1). In contrast, DS from $S$. plicata and $H$. pyriformis are potent anticoagulants due to potentiation of thrombin inhibition by HC-II. These ascidian DS have $\sim 10$-fold and $\sim 6$-fold higher activity with HC-II than native and oversulfated mammalian DS respectively (Table 1). They have no effect on factor IIa- or Xa-inhibition by AT. These highly sulfated ascidian DS show that they require very selective sulfation sites to promote the HC-II interactions and, consequently, their highly specific anticoagulant properties are intimately related to their sulfation levels (Table 1 vs. Figure 2F).

\section{Concluding remarks}

The examples cited in this work clearly show how the structural features of marine homopolysaccharides (sulfated fucans and galactans) can be used to evaluate interactions with coagulation proteins (acting as promising anticoagulant or antithrombotic reagents). It was observed that the carbohydrate-protein complexes are indeed stereospecific and not a mere consequence of charge density. It is important to note that the glycosidic structural characteristics examined individually in the sections above do not really account independently and/or exclusively for the biological actions or molecular interactions. Obviously the active or inactive conformations of these homopolysaccharides arise from the presence of all structural features acting together, which comprise the "final code" required for high-affinity interactions with the target proteins. However, specific or major structural features of the carbohydrates certainly act as preponderant regulators of biological functions, as succinctly described in this work. 


\section{References}

Alves A-P, Mulloy B, Diniz JA, Mourão PA 1997. Sulfated polysaccharides from the egg jelly layer are speciesspecific inducers of acrosomal reaction in sperms of sea urchins. J Biol Chem 272: 6965-6971.

Alves A-P, Mulloy B, Moy GW, Vacquier VD, Mourão PA 1998. Females of the sea urchin Strongylocentrotus purpuratus differ in the structures of their egg jelly sulfated fucans. Glycobiology 8: 939-946.

Berteau O, Mulloy B. 2003. Sulfated fucans, fresh perspectives: structures, functions, and biological properties of sulfated fucans and an overview of enzymes active toward this class of polysaccharide. Glycobiology 13: 29R-40R.

Becker CF, Guimaraes JA, Mourão PA, Verli H. 2007. Conformation of sulfated galactan and sulfated fucan in aqueous solutions: implications to their anticoagulant activities. J Mol Graph Model 26: 391-399.

Castro MO, Pomin VH, Santos LL, Vilela-Silva AC, Hirohashi N, Pol-Fachin L, Verli H, Mourão PA 2009. A unique 2-sulfated \{beta\}-galactan from the egg jelly of the sea urchin Glyptocidaris crenularis: conformation flexibility versus induction of the sperm acrosome reaction. J Biol Chem 284: 18790-18800.

Coombe DR, Parish CR, Ramshaw IA, Snowden JM 1987. Analysis of the inhibition of tumour metastasis by sulphated polysaccharides. Int J Cancer 39: 82-88.

Cumashi A, Ushakova NA, Preobrazhenskaya ME, D'Incecco A, Piccoli A, Totani L, Tinari N, Morozevich GE, Berman AE, Bilan MI, Usov AI, Ustyuzhanina NE, Grachev AA, Sanderson CJ, Kelly M, Rabinovich GA, Iacobelli S, Nifantiev NE 2007. Consorzio Interuniversitario Nazionale per la Bio-Oncologia Italy. A comparative study of the anti-inflammatory, anticoagulant, antiangiogenic, and antiadhesive activities of nine different fucoidans from brown seaweeds. Glycobiology 17: 541-552.

Fareed JW, Hoppensteadt D, Bick RL 2000. An update on heparins at the beginning of the new millennium. Sem Thromb Haemost 26: 5-21.

Farias WR, Valente A-P, Pereira MS, Mourão PA 2000. Structure and anticoagulant activity of sulfated galactans. Isolation of a unique sulfated galactan from the red algae Botryocladia occidentalis and comparison of its anticoagulant action with that of sulfated galactans from invertebrates. J Biol Chem 275: 29299-29307.

Fonseca RJ, Oliveira SN, Melo FR, Pereira MG, Benevides NM, Mourão PA 2008. Slight differences in sulfation of algal galactans account for differences in their anticoagulant and venous antithrombotic activities. Thromb Haemost 99: 539-545.

Gandhi NS, Mancera RL 2008. The structure of glycosaminoglycans and their interactions with proteins. Chem Biol Drug Des 72: 455-482.
Guerrini M, Beccati D, Shriver Z, Naggi A, Viswanathan K, Bisio A, Capila I, Lansing JC, Guglieri S, Fraser B, Al-Hakim A, Gunay NS, Zhang Z, Robinson L, Buhse L, Nasr M, Woodcock J, Langer R, Venkataraman G, Linhardt RJ, Casu B, Torri G, Sasisekharan R 2008. Oversulfated chondroitin sulfate is a contaminant in heparin associated with adverse clinical events. Nat Biotechnol 10: 1-7.

Harrop HA, Rider CC, Coombe DR 1992. Sulphated polysaccharides exert anti-HIV activity at differing sites. Biochem Soc Trans 20: 163S.

Kishimoto TK, Viswanathan K, Ganguly T, Elankumaran S, Smith S, Pelzer K, Lansing JC, Sriranganathan N, Zhao G, Galcheva-Gargova Z, Al-Hakim A, Bailey GS, Fraser B, Roy S, Rogers-Cotrone T, Buhse L, Whary M, Fox J, Nasr M, Pan GJ, Shriver Z, Langer RS, Venkataraman G, Austen KF, Woodcock J, Sasisekharan R 2008. Contaminated heparin associated with adverse clinical events and activation of the contact system. New Engl J Med 358: 1-11.

Melo FR, Pereira MS, Foguel D, Mourão PA. 2004. Antithrombin-mediated anticoagulant activity of sulfated polysaccharides: different mechanisms for heparin and sulfated galactans. J Biol Chem 279: 20824-20835.

Mourão PA 2004. Use of sulfated fucans as anticoagulant and antithrombotic agents: future perspectives. Curr Pharm Design 10: 967-981.

Mourão PA 2007. A carbohydrate-based mechanism of species recognition in sea urchin fertilization. Braz J Med Biol Res 40: 5-17.

Mourão PA, Pereira MS 1999. Searching for alternatives to heparin: sulfated fucans from marine invertebrates. Trends Cardiovasc Med 9: 225-232.

Mourão PA, Perlin AS 1987. Structural features of sulfated glycans from the tunic of Styela plicata (ChordataTunicata). A unique occurrence of L-galactose in sulfated polysaccharides. Eur J Biochem 166: 431-436.

Mulloy B, Ribeiro A-C, Alves AP, Vieira RP, Mourão PA 2004. Sulfated fucans from echinoderms have a regular tetrasaccharide repeating unit defined by specific patterns of sulfation at the 0-2 and 0-4 positions. $J$ Biol Chem 269: 22113-22123.

Pavão MS 2002. Structure and anticoagulant properties of sulfated glycosaminoglycans from primitive Chordates. An Acad Bras Cien 74: 105-112.

Pavão MS, Aiello KR, Werneck CC, Silva LC, Valente AP, Mulloy B, Colwell NS, Tollefsen DM, Mourão PA 1998. Highly sulfated dermatan sulfates from Ascidians. Structure versus anticoagulant activity of these glycosaminoglycans. J Biol Chem 273: 27848-27857.

Pavão MS, Mourão PA, Mulloy B, Tollefsen DM 1995. A unique dermatan sulfate-like glycosaminoglycan from ascidian. Its structure and the effect of its unusual sulfation pattern on anticoagulant activity. $\mathrm{J} \mathrm{Biol} \mathrm{Chem}$ 
270: 31027-31036.

Pereira MG, Benevides NM, Melo MR, Valente A-P, Melo FR, Mourão PA 2005. Structure and anticoagulant activity of a sulfated galactan from the red alga, Gelidium crinale. Is there a specific structural requirement for the anticoagulant action? Carbohydr Res 340: 2015-2023.

Pereira MS, Melo FR, Mourão PA 2002. Is there a correlation between structure and anticoagulant action of sulfated galactans and sulfated fucans? Glycobiology 12: 573580 .

Pereira MS, Vilela-Silva A-C, Valente A-P, Mourão PA 2002b. A 2-sulfated, 3-linked alpha-L-galactan is an anticoagulant polysaccharide. Carbohydr Res 337: 2231-2238.

Pereira MS, Mulloy B, Mourão PA 1999. Structure and anticoagulant activity of sulfated fucans. Comparison between the regular, repetitive, and linear fucans from echinoderms with the more heterogeneous and branched polymers from brown algae. J Biol Chem 274: 76567667.

Pomin VH 2008. Review: an overview about the structure-function relationship of marine sulfated homopolysaccharides with regular chemical structures. Biopolymers 91: 601-609.

Pomin VH 2009. Structural and functional insights into sulfated galactans: a systematic review. Glycoconj J 27: 1-12.

Pomin VH, Mourão PA. 2008. Structure, biology, evolution, and medical importance of sulfated fucans and galactans. Glycobiology 18: 1016-1027.

Santos JA, Mulloy B, Mourão PA 1992. Structural diversity among sulfated alpha-L-galactans from ascidians (tunicates). Studies on the species Ciona intestinalis and Herdmania monus. Eur J Biochem 204: 669-677.

Vicente CP, Zancan P, Peixoto LL, Alves-Sá R, Araújo FS, Mourão PA, Pavão MS 2001. Unbalanced effects of dermatan sulfates with different sulfation patterns on coagulation, thrombosis and bleeding. Thromb Haemost 86: $1215-1220$.

Vilela-Silva A-C, Alves A-P, Valente A-P, Vacquier VD, Mourão PA 1999. Structure of the sulfated alpha-L-fucan from the egg jelly coat of the sea urchin Strongylocentrotus franciscanus: patterns of preferential 2-O- and 4-Osulfation determine sperm cell recognition. Glycobiology 9: 927-933.

Vilela-Silva A-C, Castro MO, Valente A-P, Biermann $\mathrm{CH}$, Mourão PA 2002. Sulfated fucans from the egg jellies of the closely related sea urchins Strongylocentrotus droebachiensis and Strongylocentrotus pallidus ensure species-specific fertilization. J Biol Chem 277: 379387.

Vilela-Silva A-C, Hirohashi N, Mourão PA 2008. The structure of sulfated polysaccharides ensures a carbohydratebased mechanism for species recognition during sea urchin fertilization. Int J Dev Biol 52: 551-559.

\section{*Correspondence}

\section{Vitor H. Pomin}

Institute of Medical Biochemistry, UFRJ

Rua Professor Rodolpho Paulo Rocco, 255, HUCFF 4A01

pominvh@bioqmed.ufrj.br

Tel.: +552125622939

Fax:+ 552125622090 